\title{
A IMPORTÂNCIA DA COMUNICAÇÃO INTERNA NAS ORGANIZAÇÕES E A GESTÃO DO CONHECIMENTO
}

\author{
Michel Sales Silva ${ }^{1}$ \\ Regina Correa de Moraes ${ }^{2}$ \\ Tania Regina Galvão Mancilha ${ }^{3}$ \\ Braz Antonio Rodrigues ${ }^{4}$ \\ Rogério dos Santos Morais ${ }^{5}$ \\ José Dirnece Paes Tavares ${ }^{6}$
}

\begin{abstract}
Resumo: Esse trabalho discute sobre a importância da comunicação interna nas organizações atuais, e objetiva trazer maiores contribuições e condições para auxiliar na gestão dos colaboradores e alavancar melhores resultados. O propósito deste estudo é compreender o uso e o conhecimento que os gestores possuem das ferramentas da comunicação. O clima de conflito foi constatado sobretudo pela falta de integração entre os colaboradores internos $x$ externos, o que de fato prejudicou sobremaneira a organização estudada. Um novo modelo de comunicação deve ser incentivado, objetivando quebra de paradigmas, reduzindo ou até eliminando dessa forma o tabu do relacionamento. No desenvolver desse estudo foi identificada a dificuldade que a organização em pauta tem em praticar e estimular a comunicação interna. Palavras-chave: Comunicação Interna; Gestão do Conhecimento; Relacionamento Interpessoal.
\end{abstract}

\footnotetext{
${ }^{1}$ Administração/Anhanguera de Jacareí SP, Brasil. E-mail: michel.sales@bol.com.br.

2 Administração/Anhanguera de Jacareí SP, Brasil. E-mail: profareginamoraes@gmail.com.

3 Administração/Anhanguera de Jacareí SP, Brasil. E-mail: taniamancilha@yahoo.com.br.

${ }^{4}$ Administração/Anhanguera de Jacareí SP, Brasil. E-mail: braz.antonio@anhanguera.com.

${ }^{5}$ Administração/ Universidade Braz Cubas, Brasil. E-mail: rogeriosmorais@uol.com.br.

${ }^{6}$ Administração/Anhanguera de Jacareí SP, Brasil. E-mail: dirluci@uol.com.br.
} 